\title{
Violation of traffic safety when using chloride dir in railway transport
}

\author{
Vladimir Popov ${ }^{1}$, Svetlana Churiukina $^{1 *}$, Philipp Sukhov ${ }^{1}$, Yuri Borovkov ${ }^{1}$, Julia \\ Balandova $^{1}$ \\ ${ }^{1}$ Russian University of Transport RUT (MIIT), Obraztsova str. 9, b.9, Moscow, 127994, Russia
}

\begin{abstract}
This article experimentally proves the negative (destructive) effect of chloride DIR on railway transport facilities. The ways of chloride DIR getting of various objects of railway transport are shown. The relationship between the usage of chloride DIR and the violation of traffic safety in railway transport is being proven. Possible scenarios of the occurrence of a violation of traffic safety without taking into account the occurrence of human casualties are presented.
\end{abstract}

\section{Introduction}

In order to ensure the safety of passengers and railway personnel, in order to prevent economic damage and to avoid causing harm to the environment, it is necessary to provide measures to prevent traffic safety violations that may arise because of any activities. This article consider emergencies that may occur when using chloride deicing reagents (DIR) at the passenger infrastructure facilities in the cold season. According to the Orders of Russian Railways dated June 4, 2013 No. 1252r "On approval of the Standard requirements for the placement, operation, maintenance and repair of passenger facilities on railway lines" (paragraph 5.9.2. Requirements for the maintenance of passenger platforms, passages, bridges and meetings in winter), dated 10.22.2013 N 2243r (revised on 09/04/2018) "On approval of the Instructions for preparing for work in the winter and organizing snow fights on railways, in other branches and structural divisions of Russian Railways, as well as its subsidiaries and affiliates" anti-icing mixture with sand and gravel are used to combat ice. As anti-icing mixture it was proposed to use chloride deicing reagents. According to the manufacturers, these reagents are environmentally friendly, odorless (which is important since they will have to be used in crowded places), fireproof, non-toxic, convenient to use (do not require special equipment), and (according to the manufacturers) are not aggressive towards metals and concrete, which are the main materials for passenger facilities. In connection with this proposal, a letter from the Central Directorate of Passenger Arrangements dated April 29, 2014 from the Branch of JSC Russian Railways proposed to conduct studies on the real effect of chloride reagents on the main materials of which the objects of passenger equipment are made (high and low platforms, pedestrian passenger bridges, pedestrian crossings), since at these objects the usage of the above anti-icing mixtures was planned.

\footnotetext{
*Corresponding author: churukinasv@mail.ru
} 
Based on this letter, the staff of the Department of Chemistry and Engineering Ecology of the Russian University of Transport RUT (MIIT) conducted studies on the effects of the above reagents on the basic materials that make up the facilities on which these substances were planned to be used. As mentioned above, these are concrete, steel and reinforced concrete. The conclusion about the expediency and safety of the use of anti-icing reagents at enterprises and railway transport facilities was made according to the results of comprehensive studies.

\section{Methodological support of the experimental part of the study}

Evaluation of the effect of anti-icing reagents on the materials of the objects of study was carried out in accordance with the main provisions and requirements set forth in the following documents:

- GOST 9.908-85 Metals and alloys. Methods for determining indicators of corrosion and corrosion resistance, M., 1999

- GOST 5382-91 Cements and materials of cement production. Methods of chemical analysis, M., 1991

- PNDF 16.2.2: 2.3: 3.33-02. The methodology for measuring the $\mathrm{pH}$ of solid and liquid wastes of production and consumption, sediments, sludge, activated sludge, bottom sediments by the potentiometric method. - M: 2005

- PNDF 14.1: 2.96-97. Quantitative chemical analysis of water. The methodology for measuring the mass concentration of chlorides in samples of natural and treated wastewater by the argentometric method. - M., 1997

- Guidelines for determining the corrosion rate of cement stone, mortar, and concrete in corrosive liquids. M .: Stroyizdat, 1970. S.34-56. (updated on 05.21.2015).

- ASTM C-672-76, "Test for resistance to cracking of concrete surfaces when exposed to anti-icing chemicals."

The studies were carried out in the mode close to the climatic conditions of central Russia [1]. Temperature differences that occurred in the autumn and spring periods, as well as quite often in winter, were also taken into account.

\section{Experiment Results}

A concrete cracking test revealed complete destruction of the samples. In the test (ASTM C-672-76, "Test for resistance to cracking of concrete surfaces when exposed to anti-icing chemicals"), the degree of destruction of the samples are assigned points from 1 to 5 . 1 point - the smallest failure, 5 points - complete destruction. The test data are shown in table 3.

All subsequent tests confirmed that when exposed to chloride DIR on concrete, the latter will be destroyed [2].

When testing metal samples (iron and steel plates), traces of corrosion were also detected [3]. Chloride corrosion of metal structures was confirmed by a qualitative reaction to divalent ferrous ions passing into solution and showing that a redox reaction is underway, which will lead to the formation of corrosion products (see equation 1).

$$
\mathrm{Fe}-2 \mathrm{e} \rightarrow \mathrm{Fe}^{2+}
$$

When testing metal (iron) plates, an oxidation-reduction reaction proceeded, as a result of which rust subsequently forms. This was confirmed by a change in the color of the solution. Tests of iron plates were carried out as follows. The plates, previously cleaned with sandpaper, were immersed firstly in a 2-component model of anti-icing reagent, then 
in a 3-component one. Then they were maintained in solutions for an hour. Having removed the plates from the solutions, the indicator $\mathrm{K} 3[\mathrm{Fe}(\mathrm{CN})$ 6] - potassium hexacyanoferrate (3+) (2-3 drops) was added to the latter. After adding the indicator, the solution of the 2-component model of the anti-icing reagent turned yellow, with a slight greenish tint. The coloring of the three-component model was more intense. Since hexacyanoferrate is an indicator of $\mathrm{Fe} 2$ + ions, we can talk about the onset of corrosion. Iron from a neutral state with an oxidation state of 0 is converted to iron with an oxidation state of +2 (see reaction equation 1). This intermediate state and the next state of iron will already be with oxidation state +3 , i.e. the iron becomes rusty.

Table 1 The results of the degree of destruction of concrete in the models used anti-icing reagents after testing with standard values during visual inspection

\begin{tabular}{|c|c|c|c|c|c|}
\hline No & Temperature test & $\begin{array}{l}\text { Determination } \\
\text { result }\end{array}$ & $\begin{array}{l}\text { Normative } \\
\text { value }\end{array}$ & $\begin{array}{l}\text { Determination } \\
\text { result }\end{array}$ & Notes \\
\hline \multirow[b]{2}{*}{1} & \multirow{2}{*}{$\begin{array}{l}\text { Constant positive } \\
\text { temperatures in the range } \\
\text { from } 0 \text { to } 25^{\circ} \mathrm{C}\end{array}$} & $\begin{array}{l}\text { 2-component } \\
\text { model }\end{array}$ & 1 points & \multirow[b]{2}{*}{$0-1$} & $\begin{array}{l}\text { The initial stage of } \\
\text { destruction }\end{array}$ \\
\hline & & $\begin{array}{l}\text { 3-component } \\
\text { model }\end{array}$ & $\begin{array}{l}\text { more than } 1 \\
\text { but } 2 \text { less } \\
\text { points }\end{array}$ & & $\begin{array}{l}\text { The initial stage of } \\
\text { destruction }\end{array}$ \\
\hline \multirow[b]{2}{*}{2} & \multirow{2}{*}{$\begin{array}{l}\text { Constant negative } \\
\text { temperatures in the range } \\
\text { from }-12 \text { to }-18{ }^{\circ} \mathrm{C}\end{array}$} & $\begin{array}{l}\text { 2-component } \\
\text { model }\end{array}$ & 5 points & $0-1$ & $\begin{array}{l}\text { Strong } \\
\text { destruction. } \\
\text { Concrete } \\
\text { corroded }\end{array}$ \\
\hline & & $\begin{array}{l}\text { 3-component } \\
\text { model }\end{array}$ & $\begin{array}{l}\text { More than } 5 \\
\text { points }\end{array}$ & $0-1$ & $\begin{array}{lr}\text { Very } & \text { strong } \\
\text { destruction. } \\
\text { Strong corrosion } \\
\text { of } \quad \text { concrete } \\
\text { occurred }\end{array}$ \\
\hline \multirow{2}{*}{3} & \multirow{2}{*}{$\begin{array}{l}\text { Constant negative } \\
\text { temperatures in the range } \\
\text { from }-12 \text { to }-18 \\
{ }^{\circ} \mathrm{CCyclical} \text { temperature } \\
\text { changes from negative to } \\
\text { positive }\end{array}$} & $\begin{array}{l}\text { 2-component } \\
\text { model }\end{array}$ & $\begin{array}{l}\text { much more } \\
\text { than } 5 \text { points }\end{array}$ & $0-1$ & $\begin{array}{lr}\text { Almost complete } \\
\text { destruction } \\
\text { concrete. Intense } \\
\text { corrosion }\end{array}$ \\
\hline & & $\begin{array}{l}\text { 3-component } \\
\text { model }\end{array}$ & & $0-1$ & $\begin{array}{l}\text { Almost complete } \\
\text { destruction } \begin{array}{r}\text { of } \\
\text { concrete. Intense } \\
\text { corrosion }\end{array}\end{array}$ \\
\hline
\end{tabular}

Based on the obtained experimental data, it was concluded that chloride deicing reagents, contrary to the claims of manufacturers, will destroy the basic materials - the basis of the studied objects of passenger infrastructures.

However, the objects of passenger infrastructures are not separate structures, they form a single organism with other objects: with the upper structure of the railway track, the overhead lines of the electrification contact network, even with the rolling stock that moves along the path. The composition of all the above objects also includes concrete and metals based on iron. Therefore, deicing reagents can affect not only those objects on which they are directly used, but also objects adjacent to them. On railway tracks reagents will fall naturally: just fall from passenger platforms, pedestrian bridges, stairs, etc. Since the path consists of sleepers (concrete) and rails (steel-based iron), then the path will also be destroyed.

From open pedestrian bridges during direct application, as well as in windy weather, reagents will fall on the elements of overhead lines of the electrification contact network. The authors of the article carried out laboratory studies in which the processes of mass transfer of chloride reagents at different wind speeds were simulated [4]. The intensity of mass transfer was calculated by equation (2), which was derived from the Bernoulli equation (see equation 3). 


$$
\mathrm{j}=\mathrm{cu}
$$

where $\mathrm{C}$ (fraction of a unit) is the concentration of the substance in the air flow $\mathrm{mg} / \mathrm{m}^{3}, \mathrm{u}$ is the air flow velocity, $\mathrm{m} / \mathrm{s}$.

$$
u=\sqrt{\frac{2\left(P_{0}-P\right)}{\rho}}
$$

where $\mathrm{u}$ is the air flow velocity, $\mathrm{m} / \mathrm{s}$; P0 is the air pressure at $\mathrm{n}$. u., $\mathrm{mm} \mathrm{Hg}$. p-atmospheric air pressure, mm Hg. $\mathrm{p}$ - density of air, $\mathrm{mg} / \mathrm{m}^{3}$.

The experiment was carried out on a laboratory aerodynamic installation (see Fig. 1)

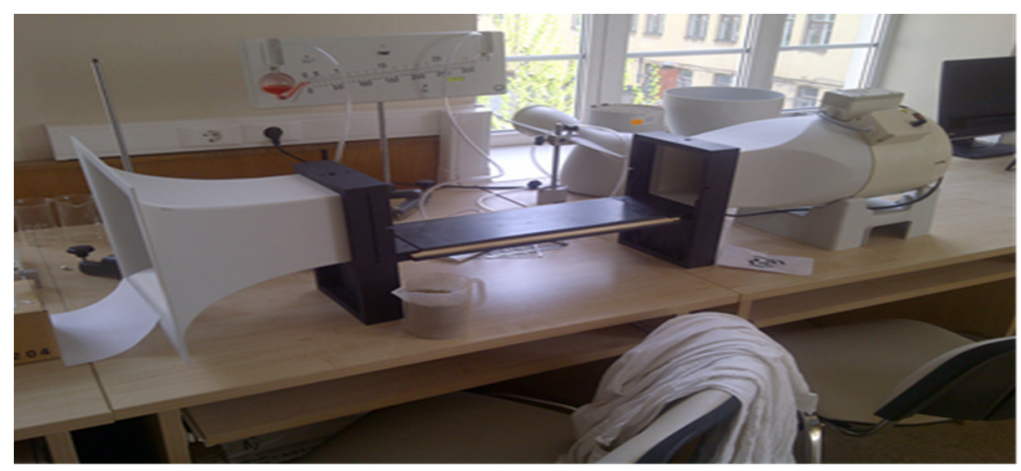

Fig. 1. Installation for determining mass transfer (Venturi).

The experimental data are listed in table 2.

Table 2. Dependence of the mass transfer values of the model of chloride deicing reagent on the air velocity

\begin{tabular}{|l|l|l|l|l|}
\hline $\mathrm{U}, \mathrm{m} / \mathrm{c}$ & 1,0 & 1,3 & 2,1 & 5,0 \\
\hline $\mathrm{c} 10^{-3}, \mathrm{M \Gamma} / \mathrm{M}^{3}$ & 0 & 1,02 & 2,65 & 15,07 \\
\hline $\mathrm{j} 10^{-3}$ & 0 & 1,325 & 5,58 & 75,35 \\
\hline
\end{tabular}

A graph was built of the dependence of concentration values on the air velocity. It is presented on Figure 2.

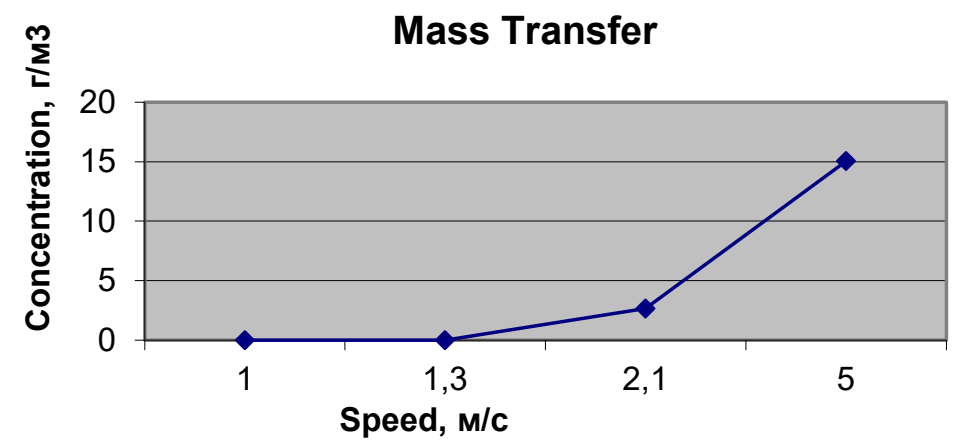

Fig. 2 The dependence of the concentration of chloride reagents on the speed of air movement.

According to the data of Table 1 and Figure 2, it can be seen that with an wind speed increase, the amount of substance transferred to it also increases.

The experimental data prove that when using chloride reagents, the latter can get on the elements of the overhead lines of the electrification contact network not only when falling from open passenger bridges, but also due to convective mass transfer. 
Contact network elements also include concrete, iron, and copper. In this regard, studies have been conducted on the effect of chlorides on copper plates. The experimental results also testified to corrosion processes on the surface of the tested copper samples $[5,6]$. Since it is accurate to predict exactly what concentration of reagents will get on the copper wires of electrification overhead lines, several values of concentrations of reagent models were laid down during the simulation of experiments. In the experiment, different concentrations of the solutions of chloride reagent models were applied to the copper wires; after that, the wires were heat-treated at a temperature of 200 degrees $C$. To this temperature, wires are usually heated by contact with the current-carrying parts of a passing electric train according to the Lenz-Joule law (see equation 4) [6].

$$
\mathrm{Q}=\mathrm{I}^{2} \mathrm{R}
$$

where $\mathrm{Q}$ is the amount of heat released during the passage of electric current through a section of the circuit; $\mathrm{I}$ is the current strength; $\mathrm{R}$ is the resistance.

The destruction of copper wires with simultaneous exposure to them of different concentrations of chloride DIR models and elevated temperature $\left(200^{\circ} \mathrm{C}\right)$ is shown in Figures 3 - 8 .

Figures $3-8$ clearly illustrate the destruction of copper wires with simultaneous exposure to solutions of chloride reagents and elevated temperature (places of destruction are indicated by arrows). The higher the concentration of the reagent, the greater the destruction.

Thus, chloride DIR will adversely affect even overhead lines, the electrification contact network.

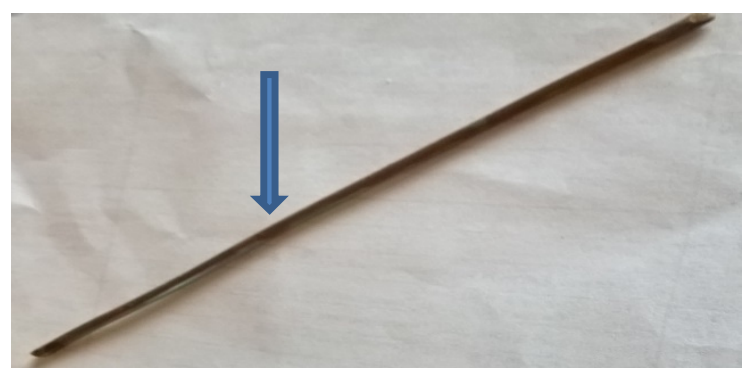

Fig. 3. View of a sample of a copper wire treated with chloride DIR of $4 \%$ concentration after heat treatment at $2000 \mathrm{C}$

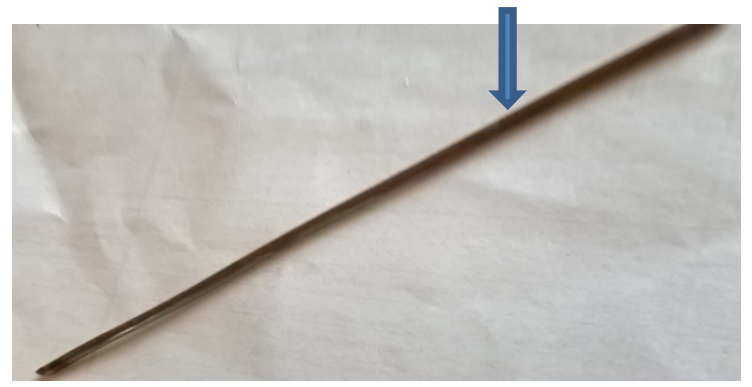

Fig 4. View of a sample of a copper wire treated with chloride DIR of $8 \%$ concentration after heat treatment at $2000 \mathrm{C}$ 


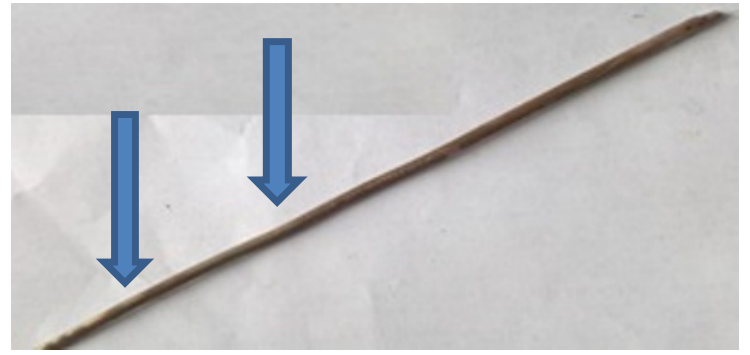

Fig. 5. View of a sample of copper wire treated with DIR chloride of $12 \%$ concentration, after heat treatment at $2000 \mathrm{C}$

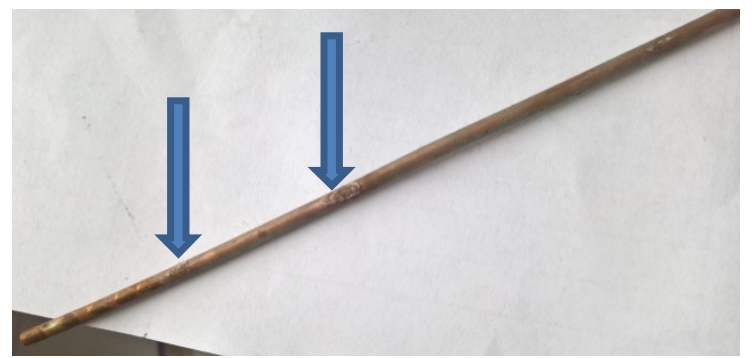

Fig. 6. View of a sample of copper wire treated with chloride DIR of $16 \%$ concentration, after heat treatment at $2000 \mathrm{C}$

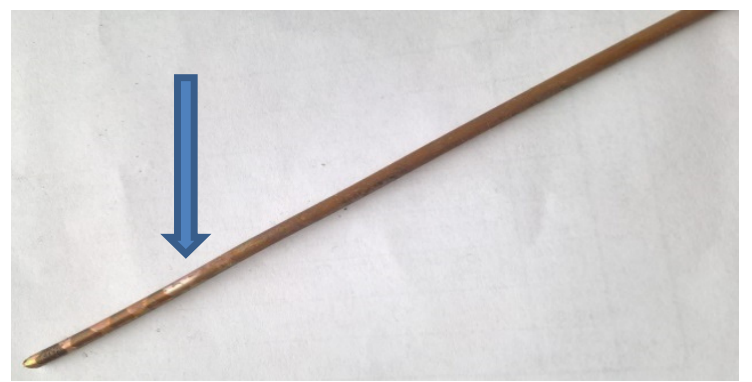

Fig. 7. View of a sample of copper wire treated with chloride DIR of $20 \%$ concentration, after heat treatment at $2000 \mathrm{C}$

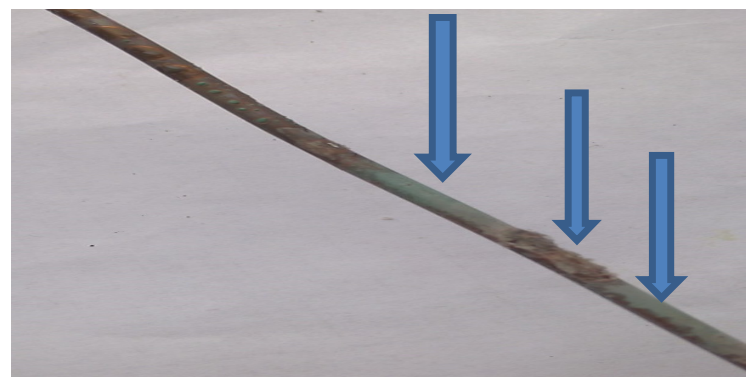

Fig. 8. View of a sample of copper wire treated with chloride DIR $30 \%$ concentration, after heat treatment at $2000 \mathrm{C}$

Particular attention should be paid to the fact that each test ended with the destruction of the test sample, whether it be a concrete sample, or a sample of copper wire, or iron plates. Therefore, the destruction of various objects of railway transport when using chloride DIR, 
as already mentioned at the beginning of this article, will occur with a high probability. This situation will certainly affect the safety of railway traffic.

\section{Identification of situations leading to a violation of railway safety when using chloride DIR}

The impacts identified during testing of samples of materials, the main important objects of railway transport consist of will lead to accidents that will have a very negative impact on traffic safety and cause not only economic damage, but also cause human casualties. The authors of the article carried out identification of possible emergency situations that are capable of provoking chloride deicing reagents. When using chloride reagents, the destruction of passenger facilities (platforms, pedestrian bridges over railways, crossings) will occur. The destruction of the track's upper structure will also occur due to the destruction of rails and sleepers. Electrification overhead lines will collapse. When chloride DIR hits the rails, the undercarriage of the trains will be destroyed. The following sequences can be made that affect traffic safety, without taking into account the possibility of human casualties:

1. The use of chloride DIR at passenger infrastructure facilities $\rightarrow$ destruction of passenger facilities $\rightarrow$ falling pieces of concrete and reinforcement on the way $\rightarrow$ train obstruction

2. The use of chloride DIR on passenger infrastructure facilities $\rightarrow$ getting DIR on rails and sleepers $\rightarrow$ destruction of objects of the upper track structure (rails, sleepers) $\rightarrow$ distortion of the geometry of the track $\rightarrow$ derailment

3. The use of chloride DIR on passenger infrastructure facilities $\rightarrow$ getting DIR on rails and sleepers $\rightarrow$ getting DIR on chassis of trains $\rightarrow$ destruction of the chassis of trains (wheelsets, axles, etc.) $\rightarrow$ derailment of trains

4. The use of chloride DIR on passenger infrastructure facilities $\rightarrow$ DIR hit on elements of overhead lines of electrification networks $\rightarrow$ destruction of electrification networks $\rightarrow$ increase the interval in train traffic

$\rightarrow$ derailment of rails

Similar incidents occur frequently. However, this is not always covered by the media all over the world. Very often, experts cannot explain the reasons for the occurrence of such situations. Sometimes the cause of the accident is represented by climatic conditions, which causes skepticism of some experts, although these judgments are not far from the truth. But, nevertheless, there is an example of such accidents - the collapse of the platform of the Vyshgorodskaya railway station in Kiev [7]. The destruction of wires in St. Petersburg [8]. Destruction of railway transport facilities was noted as far back as in the USSR, where sodium chloride and sand were mainly used to combat icing at passenger facilities, [9].

\section{Conclusion}

This topic requires serious research. Rail transport is an object of increased danger and violation of traffic safety is a serious problem, especially according to the results of experimental data, this is a complex problem. During tests, it was revealed that chloride DIRs are able to disable numerous railway transport facilities, which will lead to their destruction. Such objects include:

- $\quad$ passenger platforms high and low;

- passenger pedestrian crossings;

- passenger footbridges;

- rails; 
- sleepers;

- wheelsets and axles of trains.

Integrated measures must be developed to improve security.

\section{References}

1. Geography of Russia: Encyclopedic Dictionary. M., (1998).

2. V. Popov, S. Churiukina: International Conference Proceeding, 4(22), 1, 25-28. (2016).

3. F. Todt, Corrosion and corrosion protection Moscow; Leningrad: Chemistry, 847 p., (1966)

4. V.G. Popov, F.I. Sukhov, S.V. Churyukina, D.I. Duseyev, Materials III - IV international scientific-practical conference. The monthly Russian-Chinese scientific journal "Commonwealth" 4 (3), 1 (2016)

5. Railway directory. The development of the resource takes place as part of the project "ZhD.RF community of railway transport professionals. - [Online]. Available: http://вики.жд.рф/ (2018)

6. V. Popov, A. Sukhov, S. Churiukina, D. Duseev. International Research Journal. 7 (61), 65-68 (2017).

7. Glavred.info. [Online]. Available: https://glavred.info/stolica/246998-vlasti-kieva-nazvaliprichinu-obrusheniya-perrona-vinovata-pogoda.html. (2013).

8. O.V. Mosin. On the benefits and harms of anti-icing products. [Online]. Available: http://www.o8ode.ru/article/krie/noice/article.htm - (2019).

9. Wikipedia Contributors, "List of Russian rail accidents," Wikipedia, [Online]. Available: https://ru.wikipedia.org/w/index.php?title=Железнодорожные_происшествия_в_Российской _Федерации. (2018) 